\title{
Steam gasification for waste valorization with energy recovery
}

\author{
Włodzimierz Szczepaniak ${ }^{1}$, Monika Zabłocka-Malicka ${ }^{2}$, and Agnieszka Gurgul ${ }^{1, *}$ \\ ${ }^{1}$ Wrocław University of Technology, Faculty of Environmental Engineering, Wybrzeże \\ Wyspiańskiego 27, 50-370 Wrocław, Poland \\ ${ }^{2}$ Wrocław University of Technology, Faculty of Chemistry, Wybrzeże Wyspiańskiego 27, \\ 50-370 Wrocław, Poland
}

\begin{abstract}
Steam gasification seems a promising technology of waste transformation since the steam is the only oxidizing reagent in the process and gaseous carrier of volatiles. Gasses are equilibrated at high temperature for conversion to the $\mathrm{H}_{2}$-rich syngas. After this step, the excess of steam condenses during cooling, together with non-converted tars, oils and fine particles. Condensing steam efficiently absorbs hydrogen bromide and hydrogen chloride. The use of steam eliminates carbonaceous residue from the solid mineral/metal product, which is convenient for further processing (for example extraction of metals). The syngas and the solid residue are generally the only products of gasification, because aqueous condensate may be returned to the process together with non-volatile hydrocarbons and sediments. The process was illustrated by laboratory scale gasification experiments with a) carton packaging, b) abrasive disc, c) pork bones, d) $\mathrm{Cu}$ multiwire cable e) PC/AT card and f) inverter (PCB board). The mineral/metal products of gasification may be considered as a raw materials for further processing, including typical routes of metals recovery. There is no direct emission to the atmosphere from the process. However, providing the energy from the syngas back to the reactor as well as the energy balance of steam condensation and recirculation of condensate to the reactor need careful analysis.
\end{abstract}

\section{Introduction}

According to EU Directive 2008/98/EC, 'waste' means any substance or object which the holder discards or intends or is required to discard. These substances and objects are made from original, irreversibly transformed, natural mineral deposits. Despite the transformation, wastes are considered as a potential source of non-natural raw materials. However, their use is limited due to physical and chemical properties as well as complexity. Mechanically processed still exhibit properties which were created during the process of production, but their quality as raw materials is substantially reduced. In order to increase valorization of wastes it is necessary to move from recycling of the macro form (items or

\footnotetext{
*Corresponding author: agnieszka.gurgul@pwr.edu.pl
} 
materials) to the micro one (elements or substances), similarly to processing of natural raw materials.

The advanced processing of wastes should be preceded by the removal of organic components (e.g. plastics, resin binders, clothes, etc.), which are usually one of the waste components. The efficient removal is possible by mechanical or chemical processes (depending on whether organic components are integrated with metal/mineral components or not). Chemical methods may be realized as the low-temperature (aqueous or nonaqueous leaching) or the high-temperature ones, i.e., incineration, pyrolysis or gasification. On special attention deserves gasification, and specifically steam gasification. These processes allow for energy recovery, because released gasses may be used for chemical synthesis or energy generation (chemical energy carrier). Steam gasification seems exceptional due to physicochemical properties of the oxidant, i.e. water. This commonly available reagent is also gaseous carrier which excess may be separated by condensation and returned to the process. As a result, there is no immediate emission to atmosphere and gasses usually enriched in hydrogen may be applied not only for energy generation but also as the syngas. Consumption of water in the process (of any quality) should also eliminate potential wastewaters. Steam gasification seems, therefore, the waste-free process if solid products of gasification will be fully utilized. Few laboratory experiments of steam gasification are presented below.

\section{Processes of gasification}

\subsection{Materials and methods}

The process of steam gasification was illustrated by laboratory scale experiments with a) carton packaging, b) abrasive disc, c) pork bones, d) $\mathrm{Cu}$ multiwire PVC cable e) PC/AT card and f) inverter (PCB board).

These experiments were carried out in tubular quartz reactors (inner diameter of $36 \mathrm{~mm}$ ) with at least two individually heated zones: gasifying and equilibration. Gasified materials placed in the former one was separated from the later by perforated steel or thin quartz wool barriers. The steam was generated inside the reactor from water supplied by peristaltic pump in an excess. Vertical reactors were closed by a water seal on the gasified material side and with temperature resistant siloxane layers on the side of equilibration zone. Horizontal reactor was closed with siloxane layers on the both sides. Heating of zones of reactors was performed with electronic controllers RE31 or RE15 with SSR units and K-type thermocouples (LUMEL S.A., Poland). Temperatures in the reactor zones were registered with digital recorder APAR AR 206/8 (Poland). Gasses from the process were leaving reactor by the glass outlet to the Liebig condenser and then were washed in an alkaline scrubber and combusted in a micro flare.

Because it was assumed that the amount of oils and tars should be minimized in the process, gasses flowing from the gasification zone were heated in the so-called equilibration zone up to $800-900^{\circ} \mathrm{C}$ (usually with maximum gas emission at $250-450^{\circ} \mathrm{C}$ ). To enhance the gas mixing and equilibration, the equilibration zone was filled with porous granules of several millimeters in the diameter, prepared from the local clay [1]. The residence time of the gas in the equilibration zone, was roughly equal to $0.2-0.5 \mathrm{~s}$. Cooling gasses in the Liebig condenser caused condensation of the steam excess, gathered in glass containers.

Experiments were started with overnight heating of the reactor at temperatures (roughly) $100^{\circ} \mathrm{C}$ for gasification zone and $150^{\circ} \mathrm{C}$ for equilibration zone. In the next step, the temperature of the equilibration zone was increased and steam generation was turned on. 
A relatively slow heating of the gasification zone (few degrees per minute) was started somewhat later so that the beginning of the gas emissions from the gasified sample was correlated with the required temperature of the conversion zone. The heating of the gasification zone was continued up to the temperature maximum (lower for carton packaging, higher for other samples). Then the temperature was stabilized and gasification was continued to an almost complete decay of the gas emission. At the end of the experiments, the reactor was cooled down, the water supply was stopped at $500-600^{\circ} \mathrm{C}$ and the temperature of gasifying / equilibration zones was lowered to slightly above $100^{\circ} \mathrm{C}$ (to avoid steam condensation). Finally, reactors were opened and solid products, as well as ceramic granules, were removed.

Because general composition of the gaseous phase from steam gasification in equilibrium (or close to equilibrium) is well known, properties of this phase was not analyzed. The attention was paid to the aqueous condensate (together with sediments in the Liebig condenser), ceramic granules from the equilibration zone and, in the first place, to the solid residue - the basic product of the process. These phases were investigated by classical chemical analysis, GC-MS, XRD or SEM, depending on the waste type.

The HSC Chemistry 6.12 software of Outotec Research Oy was used for thermodynamic calculations. A simplified procedure of calculation included: (a) evaluation of proximate and ultimate composition, (b) calculation of the steam gasification equilibria at $850^{\circ} \mathrm{C}$ up to complete elimination of elemental carbon, (c) evaluation of supplementary water necessary for complete gasification, (d) evaluation of a standard volume of the gas (dry), its HHV and basic composition, (e) increase of the gas energy assuming the reaction: $\mathrm{C}_{(\mathrm{s})}+\mathrm{H}_{2} \mathrm{O}_{(\mathrm{l})}=\mathrm{H}_{2(\mathrm{~g})}+\mathrm{CO}_{(\mathrm{g})}$. The pressure of $10^{5} \mathrm{~Pa}(1 \mathrm{bar})$ and temperature of $25^{\circ} \mathrm{C}$ were adopted as a standard state.

\subsection{Carton packaging}

The process of the carton packaging gasification [2] was carried out in a vertical reactor with two zones: a single gasifying and equilibration. The highest temperature of the gasifying zone was $560^{\circ} \mathrm{C}$ - selected due to melting temperature of $\mathrm{Al}$ metal. The temperature of the conversion zone was stabilized at approximately $870^{\circ} \mathrm{C}$. A sample of $15.0 \mathrm{~g}$ of the carton packaging was used in the experiment. The solid products of gasification contained partially corroded pieces of aluminum foil and gray powder, which changed colour to white-gray and reduced its mass by $44 \%$, after firing in the air. The original sample and products of the process are presented in Fig. 1, together with the mass balance. The conversion of hydrocarbons to non-condensing species was efficient; according to GC-MS analysis there was only $1.57 \mathrm{mg}$ of organic compounds in the aqueous condensate (approximately $0.012 \%$ of the gasified mass of the sample). The main components of this phase were: fluoranthene (34\% of the organic species), naphthalene $(27 \%)$ and phenanthrene $(15 \%)$. The volume and heating value of gas was calculated assuming that the gasified packaging was composed of $85.62 \%$ organic fraction (including $47.33 \% \mathrm{C}, 7.71 \% \mathrm{H}, 30.26 \% \mathrm{O}, 0.26 \% \mathrm{~N}$ and $0.06 \% \mathrm{~S}$ ) [3]; the rest was aluminum and ash. According to the equilibrium model, gasification of $100 \mathrm{~kg}$ of the carton packaging would provide $239 \mathrm{~m}^{3}$ of the dry gas $\left(59 \mathrm{~mol} . \% \mathrm{H}_{2}, 39 \% \mathrm{CO}, 1 \% \mathrm{CO}_{2}\right.$ and $\left.1 \% \mathrm{CH}_{4}\right)$ with $\mathrm{HHV}$ of $11.6 \mathrm{MJ} / \mathrm{m}^{3}$. The energy from the water consumption in the gasification process was estimated to be $12.9 \%$ of the total energy of the gas. 


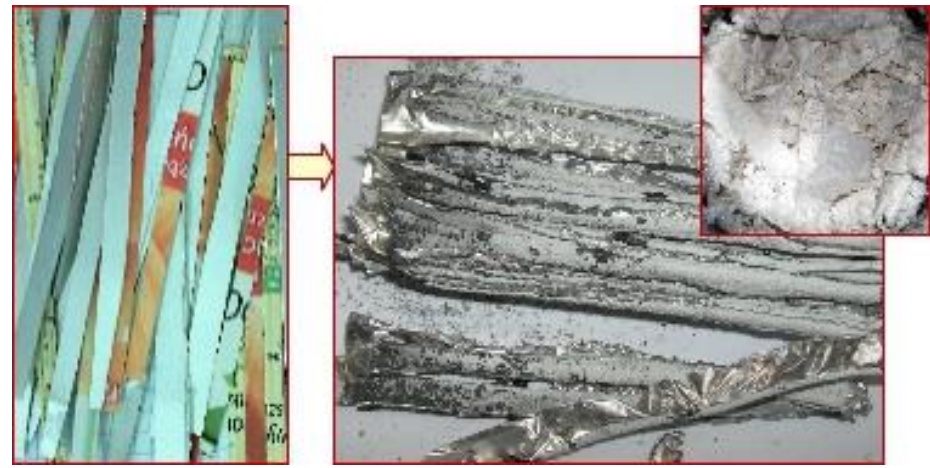

Fig. 1. The carton packaging original sample (100\%, left) and solid products of gasification aluminum foil (5.1\%, right) and mineral powder (5.7\%, right corner).

\subsection{Abrasive disc}

Abrasive sheets, belts, discs, etc. are a large group of items which usually consist of small inorganic abrasive elements bonded to the cardboard or fabric base with resins. The destruction of the resin (by steam gasification) was necessary to recover the abrasive particles and was performed [4] in the reactor similar to described above for the carton packaging. From the $26.89 \mathrm{~g}$ of the original disc, only $10.29 \mathrm{~g}(38.3 \%)$ was recovered as the solid residue. This product was crushed in the agate mortar and $7.44 \mathrm{~g}(27.7 \%)$ of the violet-blue prisms (original abrasive elements) was separated. The substrate and the product are presented in Fig. 2.
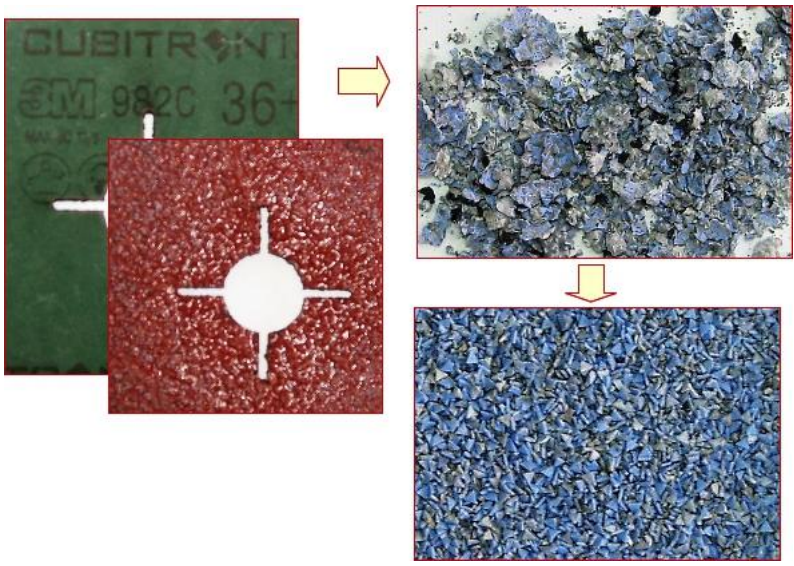

Fig. 2. The abrasive disc (100\%) and product of gasification - crude (38.3\%, right up) and separated (27.7\%, right down).

To simplify thermodynamic calculations, it was assumed that $60 \%$ of the original mass of the disc was the organic fraction dominated by epoxy resin. However, it should be kept in mind that composition of abrasive tools is not uniform and sometimes the share of inorganic compounds, including fluorides, is relatively high. Assuming again that the epoxy resin was the cured novolac one [5], it gives formally $44.59 \% \mathrm{C}, 3.75 \% \mathrm{H}, 9.37 \% \mathrm{O}, 2.17 \%$ $\mathrm{N}$ and $0.06 \% \mathrm{~S}$ in the disc sample. Calculation of the equilibrium parameters of the dry gas for these assumptions gives the following values (for $100 \mathrm{~kg}$ of the waste): $214 \mathrm{~m}^{3}$ at 
standard temperature and pressure, $56 \mathrm{~mol} . \% \mathrm{H}_{2}, 41 \% \mathrm{CO}, 1 \% \mathrm{CO}_{2}$ and $1 \% \mathrm{CH}_{4}$ and $\mathrm{HHV}$ of $11.5 \mathrm{MJ} / \mathrm{m}^{3}$. The energy due to the water consumption was estimated as $22.4 \%$ of the total energy of the gas. Conversion of hydrocarbons in the process also appeared very high - only $0.95 \mathrm{mg}$ of organic species was detected in the aqueous condensate $(0.006 \%$ of the weight loss during the gasification). There were: phenanthrene $(40 \%)$, pyrene $(10.5 \%)$ fluoranthene and anthracene $(8.4 \%$ each), phenols (a total of $20 \%$ ) and only $5.3 \%$ of naphthalene. High content of the sodium aluminum hexafluoride $\left(\mathrm{Na}_{3} \mathrm{AlF}_{6}\right)$ suggested possibility of the fluorine emission. However, analysis of aqueous condensate as well as equilibrium calculations revealed very low volatility of fluorine (below $1 \%$ of this element content in the sample).

\subsection{Pork bones}

Frozen bones, as received from the local slaughterhouse (Fig. 3, left), were placed in the vertical reactor with a third, individually heated zone for the steam generation. The most intensive gas evolution was observed between $350-450{ }^{\circ} \mathrm{C}$ in the gasifying zone. After gasification of $15.05 \mathrm{~g}$ - sample of frozen material, $3.40 \mathrm{~g}(22.6 \%)$ of the white-brownish residue was produced (Fig. 3, right). However, this raw meat/bone combination cannot be considered as a standardized material, therefore it was dried to constant weight at $105^{\circ} \mathrm{C}$ for 4 days, stating, the weight loss of $46.2 \%$. This dried product was analyzed for CHNS content $(34.43 \% \mathrm{C}, 5.10 \% \mathrm{H}, 6.43 \% \mathrm{~N}$ and $0.46 \% \mathrm{~S})$ and for the weight loss during incineration at $850^{\circ} \mathrm{C}(65.3 \%)$. As a result oxygen content should be equal to $18.88 \%$. Calculations of thermodynamic equilibrium gave the following standardized parameters of the dry gas: $57 \mathrm{~mol} . \% \mathrm{H}_{2}, 38 \% \mathrm{CO}, 1 \% \mathrm{CO}_{2}$ and $1 \% \mathrm{CH}_{4}$ and $\mathrm{HHV}$ of $11.3 \mathrm{MJ} / \mathrm{m}^{3}$. The energy due to the water consumption was equal to $14.7 \%$ of the total energy of the gas. Of course, the volume of the gas per $100 \mathrm{~kg}$ of the substrate differed between the standardized and the original material and was equal to $178 \mathrm{~m}^{3}$ and $95.6 \mathrm{~m}^{3}$, respectively. Quantitative analysis of the aqueous condensate was not performed - the condensate was only slightly yellowish, has neutral $\mathrm{pH}$ and characteristic smell. However, comparison of the peak areas in the GC-MS diagram revealed that benzonitrile was a dominant compound in the condensate $(40 \%)$ accompanied by naphthalene (15\%). Participations of other organic species (including pyridine, pyrrole, indole, quinoline etc.) were lower than $10 \%$ (each).

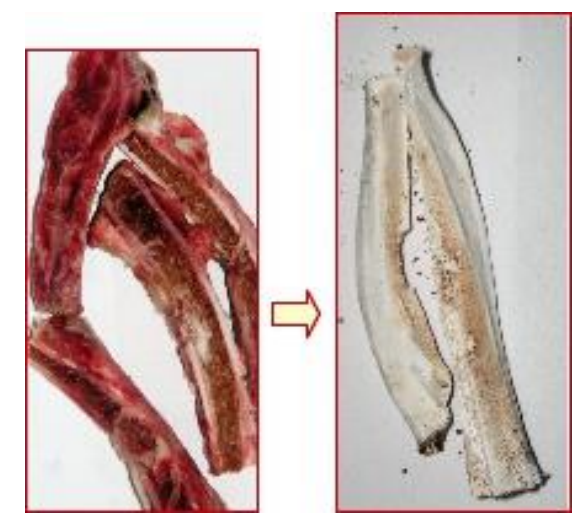

Fig. 3. Raw meat/bone substrate (100\%) and product of gasification (22.6\%). 


\subsection{Cu multiwire PVC cable}

The experiment of gasification was performed with commercial, copper multiwire cable, typical for data transfer (Fig. 4) [6]. Mass of the sample was equal to $63.5 \mathrm{~g}$, including copper cords $(25.4 \%)$, tinned copper braids (28.7\%), PVC insulations $(43.2 \%$, including polyvinyl chloride, plasticizer and calcium carbonate as filler), polyester foil (1.57\%) and cotton cords $(1.19 \%)$. The gasification process was performed in the 3 -zone reactor (as in the pork bones gasification). The presence of chlorine, estimated as $9.6 \%$ of the sample mass, was characteristic for the process. However, it appeared that approximately $1 / 4$ of $\mathrm{Cl}$ reacted with carbonate filler to $\mathrm{CaCl}_{2}, 3 / 4$ was absorbed in aqueous condensate and only less than $0.6 \%$ was found in additional alkaline scrubber (probably transferred as aerosol). The solid product of gasification was composed of $\mathrm{Cu}(89.2 \%)$ and non-metal phase $(10.8 \%)$. As it may be noticed from Fig. 4, the Cu-phase preserved the original form of cords and braids. Non-metal phase in $2 / 3$ was the calcium chloride.

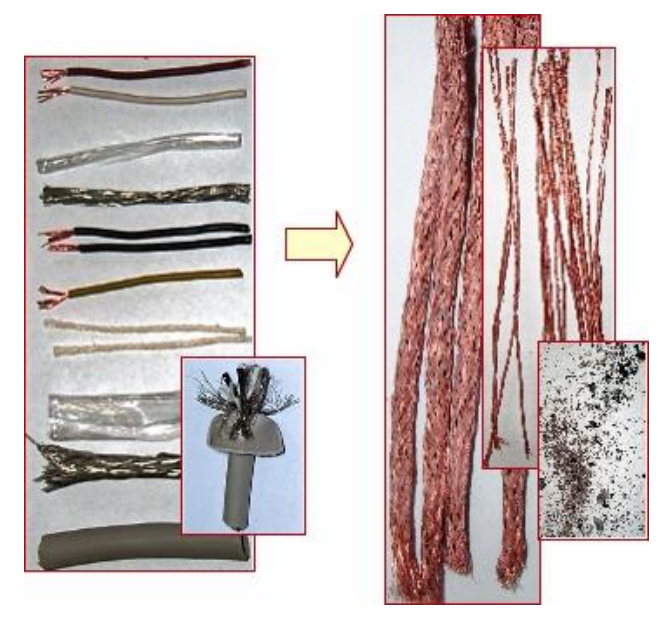

Fig. 4. Elements of the PVC multiwire Cu cable (the non-separated cable was used in the experiment) and solid products of gasification.

The content of CHONS in the cable, necessary for equilibrium calculations, was estimated on the basis of the cable composition given in [6]. For simplicity, NS was not considered due to negligible amount of cotton, hence $\mathrm{CHO}$ concentrations were equal to $19.15 \%$ for $\mathrm{C}, 2.42 \%$ for $\mathrm{H}$ and $2.88 \%$ for $\mathrm{O}$. For these parameters the volume and composition of the gas (dry and $\mathrm{HCl}$-free) was calculated as $102 \mathrm{~m}^{3}$ and $61 \mathrm{~mol} . \% \mathrm{H}_{2}, 37 \%$ $\mathrm{CO}, 1 \% \mathrm{CO}_{2}$ and $1 \% \mathrm{CH}_{4}$. HHV of the gas was equal $11.6 \mathrm{MJ} / \mathrm{m}^{3}$. Accumulation and concentrations of nonvolatile hydrocarbons were analyzed in deposits in the reactor outlet $(0.6 \%)$, Liebig condenser $(2.1 \%)$ and in the aqueous condensate (97.3\%) [6]. The compounds were dominated by polycyclic aromatic hydrocarbons, especially naphthalene $(66 \%)$, phenanthrene $(8 \%)$, and acenaphthylene $(5 \%)$. Total mass of these species was equal to $0.6 \%$ of the mass of the cable sample and $1.6 \%$ of the mass of the organic fractions (including PVC and excluding inorganic filler of the plastic).

\subsection{PC/AT card}

Gasification of the complete electronic item, 3Com TokenLink Velocity ISA card, was performed in the horizontal reactor with gas conversion, doubled gasifying and steam generation zones. The card (96.51 g) including steel support plus screws (13.48 g) and 
printed circuit board $(83.03 \mathrm{~g})$ was broken into a few pieces and placed in the reactor. Solid product of gasification (71.72 g, Fig. 5) was separated into 5 fractions: magnetic (27.8\%), large pieces of the printed circuit board ( $\mathrm{PCB}, 39.8 \%$ ), large pieces of non-magnetic fraction (19.6\%), small pieces without fine fraction $(5.7 \%)$, and fine fraction $<0.5 \mathrm{~mm}$ (7.2\%). Concentrations of metals determined for each fraction were recalculated into metals value, based on mining stocks prices (2016). The result of this evaluation (Table 1) shows that the value of the gasification product is determined primarily by $\mathrm{Au}$ and in the minor extent by $\mathrm{Cu}, \mathrm{Pd}$ and $\mathrm{Ag}$. Considering fractions individually, $39.7 \%$ of the total product value was related to the fraction of large non-magnetic pieces, $28.0 \%$ to the fraction of large pieces of PCB, $24.3 \%$ to the fraction of small non-magnetic pieces and only $4.2 \%$ to the magnetic fraction and $3.5 \%$ to the fine fraction. However, it should be kept in mind that gasified ISA card is only an example from large variety of electronic wastes.

Table 1. Relative share of metals in the value of the solid product of gasification.

\begin{tabular}{|c|c|c|c|c|c|c|}
\hline metal & $\begin{array}{c}\text { magnetic } \\
\text { fraction }\end{array}$ & $\begin{array}{c}\text { large } \\
\text { pieces of } \\
\text { printed } \\
\text { circuit } \\
\text { board }\end{array}$ & $\begin{array}{c}\text { large pieces } \\
\text { non- } \\
\text { magnetic } \\
\text { fraction }\end{array}$ & $\begin{array}{c}\text { small pieces } \\
\text { non- } \\
\text { magnetic } \\
\text { fraction }\end{array}$ & $\begin{array}{c}\text { fine } \\
\text { fraction } \\
<\mathbf{0 . 5} \text { mm }\end{array}$ & $\begin{array}{c}\text { total } \\
\text { share }\end{array}$ \\
\hline $\mathrm{Au}$ & $1.23 \%$ & $21.49 \%$ & $35.28 \%$ & $20.15 \%$ & $2.18 \%$ & $80.34 \%$ \\
\hline $\mathrm{Cu}$ & $0.33 \%$ & $3.48 \%$ & $1.77 \%$ & $0.66 \%$ & $0.17 \%$ & $6.42 \%$ \\
\hline $\mathrm{Pd}$ & $0.18 \%$ & $1.16 \%$ & $0.58 \%$ & $2.94 \%$ & $0.38 \%$ & $5.24 \%$ \\
\hline $\mathrm{Ag}$ & $0.23 \%$ & $1.03 \%$ & $1.19 \%$ & $0.38 \%$ & $0.44 \%$ & $3.26 \%$ \\
\hline $\mathrm{Pt}$ & $1.38 \%$ & \multicolumn{2}{|c|}{ below detection } & & $0.05 \%$ & $1.43 \%$ \\
\hline $\mathrm{Ni}$ & $0.55 \%$ & $0.29 \%$ & $0.37 \%$ & $0.10 \%$ & $0.08 \%$ & $1.39 \%$ \\
\hline $\mathrm{Sn}$ & $0.16 \%$ & $0.37 \%$ & $0.38 \%$ & $0.28 \%$ & $0.09 \%$ & $1.27 \%$ \\
\hline
\end{tabular}

The total amount and composition of organic fraction in the gasified card was evaluated based on data given in [7] and analysis of bromine distribution in the experiment. The procedure of calculation was similar to described in section 2.5 . Recalculating for $100 \mathrm{~kg}$ of the original card, $\mathrm{CHO}$ concentrations were equal to $13.81 \%$ for $\mathrm{C}, 1.58 \%$ for $\mathrm{H}$ and $5.31 \%$ for $\mathrm{O}$. For these parameters, the composition of the equilibrated gas (dry and $\mathrm{HBr}$-free) was $57 \mathrm{~mol} \% \mathrm{H}_{2}, 41 \% \mathrm{CO}$ and, as usually, $1 \% \mathrm{CO}_{2}$ and $1 \% \mathrm{CH}_{4}$. The standard volume and HHV was equal to $66.9 \mathrm{~m}^{3}$ and $11.6 \mathrm{MJ} / \mathrm{m}^{3}$, respectively. Almost fifty non-volatile hydrocarbon species was detected by GC-MS analysis in the aqueous condensate and sediments in the Liebig condenser. Their relative concentrations were evaluated on the basis of peak areas in chromatograms. Phenol, naphthalene and benzonitrile appeared the main compounds $(19.8 \%, 16.0 \%$, and $10.1 \%)$. Concentration of other 14 species was in the range between 1 and $10 \%$. 


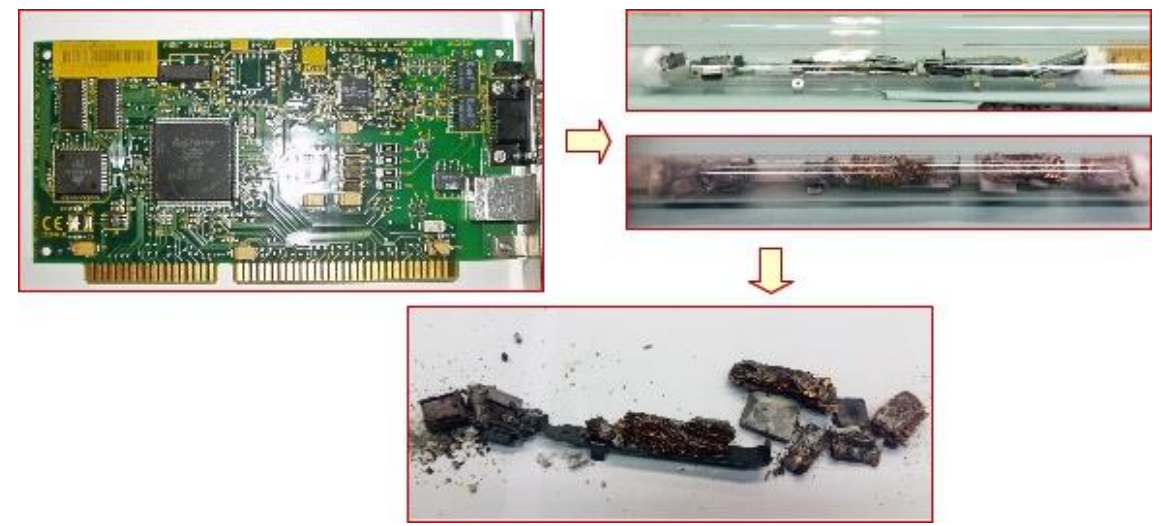

Fig. 5. Original 3Com ISA card $(96.51 \mathrm{~g})$, the card in the reactor, gasified card in the reactor, and the product of gasification $(71.72 \mathrm{~g})$.

\subsection{Inverters}

The experiment of gasification was performed with multilayer PCB boards - inverters [8]. Mass of the sample was equal to $75.71 \mathrm{~g}$ and consisted of 13 inverter boards. The gasification process was performed in the 4-zone reactor with: gas equilibration section, 2 sections of inverters processing and section of steam heating (as for PC/AT card). Steam was generated by vaporization of water fed to section with a peristaltic pump (201.SMA.150.050,WilliamsonManufacturing Company Ltd.) at the rate of $2.2 \mathrm{~g} / \mathrm{min}$. Experiment started with preheating of all reactor sections at approximately $100^{\circ} \mathrm{C}$ for $24 \mathrm{~h}$. Then section of gas conversion was heated to $850^{\circ} \mathrm{C}$ at the rate of $20^{\circ} \mathrm{C} / \mathrm{min}$. In the next step, the sample of inverters was heated at the rate of $3^{\circ} \mathrm{C} / \mathrm{min}$ also to $850^{\circ} \mathrm{C}$ and the temperature was then stabilized for $2 \mathrm{~h}$. After experiment, the reactor was cooled down to ambient temperature and solid product was removed. After gasification process solid residue weighted $61.97 \mathrm{~g}$ which equal to $81.85 \%$ of the initial weight. The single inverters became fragile, and the elements built on them became mostly detached from the surface and appeared as a loose fraction. With the removal of organic PCB bonding substances (mainly epoxy resins), the structure of the inverter has opened and it was possible to observe the individual layers from which the inverter was built - Fig. 6.
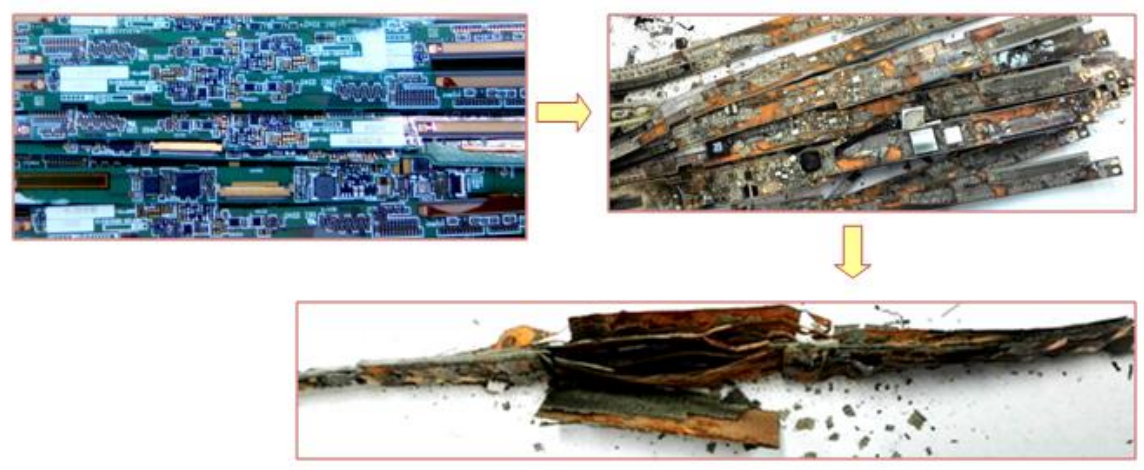

Fig.6. Samples of PCB boards (inverters) before and after gasification process with particular emphasis on the open structure of the board. 


\section{Summary}

It was shown that allothermal steam gasification of various wastes (carton packaging, abrasive disc, pork bones, $\mathrm{Cu}$ multiwire cable, PC/AT ISA card and inverter PCB board) is an efficient way of transformation into 'inorganic' solid product and 'syngas' of stable composition. The standardized composition of the equilibrated gas (dry and halogen-free) was between 56-61 mol.\% $\mathrm{H}_{2}, 38-41 \% \mathrm{CO}$ and $1 \%$ for both $\mathrm{CO}_{2}$ and $\mathrm{CH}_{4}$. $\mathrm{HHV}$ of the gas was in the range 11.3-11.6 MJ/m³ . Condensing of steam was efficient in the removal of tars and oils, as well as the absorption of $\mathrm{HCl}$ and $\mathrm{HBr}$. Moreover, short gas equilibration at high temperature enhanced conversion of hydrocarbons which resulted in the lowered concentration of non-volatile species in the aqueous condensates. These condensates could be recycled to the process for the steam generation, therefore they shouldn't be considered as waste. Solid products of the process were metals (including $\mathrm{Al}$ and $\mathrm{Cu}$ foils) and/or inorganic/metal residues, convenient for mechanical/metallurgical/chemical processing.

\section{References}

1. M. Zabłocka-Malicka, W. Szczepaniak, A. Zielińska, P. Rutkowski, Ecol. Chem. Eng. S., 23, 33-48, 2016

2. W. Szczepaniak, M. Zabłocka-Malicka, A. Zielińska, P. Rutkowski, K. Oracz, Kompleksowe Zarządzanie Gospodarką Odpadami [Integrated Waste Management], Manczarski P. (Ed.), Poznań, PZITS/oWlkp., 703-715, 2015

3. J. Haydary, D. Susa, J. Dudáš, Waste Management, 33, 1136-1141, 2013

4. A. Zielińska, W. Szczepaniak, M. Zabłocka-Malicka, P. Rutkowski, Interdyscyplinarne zagadnienia w inżynierii i ochronie środowiska. Tom 6, Kotowski A., Piekarska K., Kaźmierczak B. (Eds.), Wrocław, Oficyna Wydawnicza Politechniki Wrocławskiej, 2015, 138pdf.

5. J. Machnikowski, P. Rutkowski, M.A. Diez, J. Anal. Appl. Pyrolysis, 76, 80-87, 2006

6. M. Zabłocka-Malicka, P. Rutkowski, W. Szczepaniak, Waste Management, 46, 448-496, 2015

7. S. Kumagai, G. Grause, T. Kameda, T. Yoshioka, J. Mater. Cycles Waste Manag. (2015). doi:10.1007/s10163-015-0417-4

8. A. Gurgul, W. Szczepaniak, M. Zabłocka-Malicka, Science of The Total Environment, 624, 1119-1124, 2018 